\title{
El coche como metáfora de la relación de pareja en el cine de Carlos Saura
}

\author{
Santiago GARCÍA OCHOA \\ Doctor en Historia del Arte y Profesor (IES La Besana)
}

\begin{abstract}
RESUMEN. El presente artículo defiende la iconología fílmica como vía más apropiada para el estudio de la presencia del coche en el cine, como la única metodología capaz de desentrañar los valores que nuestra cultura asocia a este objeto tecnológico. A continuación se presenta el ejemplo del binomio relación de pareja/coche en el cine español, que puede resultar interesante para comprender mejor la evolución de la sociedad. Por último, como núcleo del artículo, se analiza la presencia del mismo binomio en el cine de Saura, concluyendo el autor que puede establecerse un código alegórico a partir de cuatro filmes: Peppermint frappé (1967), Stress es tres tres (1968), Elisa, vida mía (1976) y Los ojos vendados (1978).
\end{abstract}

Palabras clave: Cine, Automóvil, Iconología, Semiología, Carlos Saura.

ABSTRACT. This article defends filmic iconology like the most appropiate way of studying the presence of the automobile in the movies, like the unique methodology suitable to reveal the cultural senses associated to this technological object. Next, the author presents an example: the binomial couple relationship/automobile in Spanish Cinema, that may be interesting to understand the evolution of society in its entirety. Lastly, he analyses the presence of the same binomial in Carlos Saura's films and deduces the possibility of establish an allegorical code from four films: Peppermint frappé (1967), Stress es tres tres (Stress Is Three, 1968), Elisa, vida mía (Elisa, My Love, 1976) and Los ojos vendados (Blindfolded Eyes, 1978).

Key words: Cinema, Automobile, Iconology, Semiotics, Carlos Saura.

\section{MARCO METODOLÓGICO}

En su único y célebre texto dedicado al cine, Panofsky ${ }^{1}$ introduce varias pistas

\footnotetext{
${ }^{1}$ Se trata de un ensayo que conoció tres versiones impresas distintas a partir de una conferencia informal impartida a los estudiantes del departamento de Arte y Arqueología de Princeton en 1935; a saber: “On Movies", Bulletin of the Department of Art and Archeology of Princeton University, June 1936, pp. 5-15; "Style and Medium in the Moving Pictures", Transition, 26, 1937, pp. 121-33; y "Style and Medium in the Motion
}

interesantes para el desarrollo de una iconología fílmica, entre ellas: el problema de la inteligibilidad del contenido de las imágenes (confusas para los primeros espectadores del cine), base de cualquier análisis ulterior; la identificación de los mecanismos de la puesta en escena y el montaje como configuradores del estilo y el contenido

Pictures", Critique. A Review of Contemporary Art, 1.3, 1947, pp. 5-28. 
simbólico del film; la importancia de los personajes tipo y los géneros como materiales iconográficos fílmicos, aunque su procedencia sea extra-cinematográfica y/o precinematográfica ${ }^{2}$.

No obstante, su apreciación más valiosa se produce cuando pone en relación la escena de una película ( $A$ Night in Casablanca [Una noche en Casablanca, Archie L. Mayo, 1946]) con el espíritu de esa época:

"No puedo evitar el sentimiento de que la última película de los hermanos Marx Una noche en Casablanca -en la que Harpo inexplicablemente se apodera del sitio del piloto de un avión, provoca innumerables estragos al tocar uno tras otro los minúsculos instrumentos de mando, y enloquece de alegría en la misma medida en que aumenta la desproporción entre lo pequeño de su esfuerzo y la magnitud del desastre- es un símbolo magnífico y terrorífico del comportamiento humano en la era atómica. No hay duda de que los hermanos Marx rechazarían con vehemencia esta interpretación; pero lo mismo habría hecho Durero si alguien le hubiese dicho que su "Apocalipsis» prefiguraba el cataclismo de la Reforma"

Para Panofsky (aunque no lo diga) las maniobras de Harpo parecen rememorar las de los pilotos que lanzaron la bomba atómica en 1945. Son la manifestación iconográfica de un cambio cualitativo que afecta a las relaciones humanas, y viene provocado por los avances tecnológicos; o lo que es lo mismo, la agresión y satisfacción tecnológica que Marcuse describiría

\footnotetext{
${ }^{2}$ Sobre este tema interesa ver: T. Y. LEVIN, “Iconology at the movies: Panofsky's Film Theory", The Yale Journal of Criticism, 9.1, 1996, pp. 27-55; A. QUINTANA, "Los dilemas de la historia del cine frente a la historia del arte", Archivos de la Filmoteca, 35, 2000, pp. 178-96 y S. GARCíA OCHOA, "Cine e Iconología: Análisis del film desde la historia del arte", Quintana. Revista de Estudos do Departamento de Historia da Arte, 4, 2005, pp. 153-63.

${ }^{3}$ E. PANOFSKY, "El estilo y el medio en la imagen cinematográfica", en E. PANOFSKY, Sobre el estilo. Tres ensayos inéditos, Barcelona, 2000, p. 151. Resulta evidente, por la fecha de realización de la película de los hermanos Marx, que esta aportación pertenece a la última versión del artículo, la de 1947.
}

años más tarde en su célebre ensayo $\mathrm{La}$ agresividad en la sociedad industrial avanzada ${ }^{4}$.

Esta línea abierta por Panofsky en 1947 ha despertado mi interés por el estudio de la presencia de un objeto tecnológico concreto: el coche, en el cine; por intentar ahondar en lo que verdaderamente representa dentro de nuestra cultura. Las manifestaciones artísticas (incluido el cine, por supuesto) nos permiten transitar este camino, porque cuando el objeto-automóvil se introduce en ellas su practicidad queda relegada a un segundo término en favor de un nuevo valor oculto: se produce la "desocultación" heideggeriana (Unverborgenheit) y nos adentramos en la esencia misma de la cosa ${ }^{5}$.

La semiología del cine nos proporciona numerosas herramientas conceptuales imprescindibles para el estudio de la presencia del automóvil dentro del texto fílmico ${ }^{6}$. De hecho creemos que sólo tiene

-

${ }^{4}$ H. MARCUSE, La agresividad en la sociedad industrial avanzada y otros ensayos, Madrid, 1974. Cfr. S. GARCíA OCHOA, op. cit., p. 155.

${ }^{5}$ Heidegger recurre al ejemplo de un cuadro de Van Gogh que representa un par de zapatos viejos en su ensayo El origen de la obra de arte (1935-6). Puede verse M. HeIDEGGER, Arte y poesía, Madrid, 1995, p. 58 y ss.. Félix de Azúa añade otros ejemplos, como el de la locomotora, referido no sólo a cuadros de pintores como Monet, sino también a obras literarias como Ana Karenina de Tolstoi y cinematográficas como Strangers on a Train (Extraños en un tren, Alfred Hitchcock, 1951). Véase F. DE AzÚA, "voz desocultación", Diccionario de las artes, Barcelona, 1995

${ }^{6}$ A pesar de las críticas a las que se ha visto sometida la semiótica por sus dificultades a la hora de diseñar modelos aplicables a todas las obras audiovisuales, es indudable que resulta la mejor disciplina para afrontar el análisis fílmico, o al menos la que debe servir de base a cualquier metodología. Sobre todo desde la "segunda semiología" (década de los 70), que abandona el método deductivo, por abstracto e improductivo, y lo sustituye por el inductivo, mucho más operativo, ya que "fundamenta el conocimiento de la semiosis fílmica en el análisis textual de los filmes concretos. Esta nueva estrategia epistemológica que encuentra sus fundamentos en la Semiótica Narrativa, 
sentido el desarrollo de una iconología fílmica si los planteamientos de Panofsky son completados con los de la semiología del cine ${ }^{7}$. Siendo así, no resulta complicado transponer los tres niveles del célebre método iconológico panofskyano ${ }^{8}$ al análisis del film. El modelo que hemos diseñado es el siguiente:

a) Primer nivel: Impresión de realidad y participación del universo diegético. Comprende la operación de identificar y denominar los objetos reproducidos en la pantalla, así como la participación por parte del espectador del universo diegético que construye el film. Éste debe ser capaz, por lo tanto, de leer los códigos característicos del lenguaje cinematográfico (panorámica, travelín, montaje...), que han sido codificados por lo que se conoce como modelo clásico o Modo de Representación Institucionalizado (MRI), según Burch; pero que están sometidos a constantes cambios y transformaciones que son progresivamente aceptadas por el espectador como convencionales.

b) Segundo nivel: Repertorios temáticos. El espectador debe ser capaz de reconocer temas de carácter secundario o convencional que aparecen en el film. Como sucede con la obra de arte es necesario re-

provocando el rápido desarrollo de una Narratología Fílmica, parece más adecuada para abordar el estudio de la forma y el sentido de filmes concretos". Cfr. J. M. PAZ GAGO, "Teorías semióticas y semiótica fílmica", Cuadernos, 17, 2001, pp. 374-5.

${ }^{7}$ Podemos considerar la iconología como el antecedente directo de la semiología del arte y del cine. Cfr. E. CAÑIZARes FernándeZ, El lenguaje del cine: semiología del discurso fílmico, Madrid, 1992, p. 201 y ss..

${ }^{8}$ Según Heckscher el método iconológico alcanzó su pleno florecimiento en Hercules am Scheidewege und andere antike Bildstoffe in der neuren Kunst, Leipzig, Berlin, 1930. Cfr. W. S. HECKSCHER, “Erwin Panofsky: un curriculum vitae", en E. PANOFSKY, Sobre el estilo, op. cit., p. 213. Además en 1939 se publican sus célebres Studies in Iconology: Humanistic Themes in the Art of the Renaissance, New York (Estudios sobre iconología, Madrid, 1972). currir a fuentes y códigos, que para nuestro caso pueden ser cinematográficos (audiovisuales) y extra-cinematográficos (literarios, visuales, sonoros). Todas ellas constituyen el repertorio de los intertextos, que deben ser re-conocidos por el espectador/analista. La mitología clásica y la iconografía cristiana son las dos grandes fuentes que inspiran las manifestaciones figurativas del arte occidental. Siendo más precisos se pueden mencionar (a partir de Propp o Greimas) los argumentos y/o personajes universales, que se repiten con frecuencia en la literatura y el cine'; y, como código exclusivamente del cine, los géneros cinematográficos ${ }^{10}$.

\footnotetext{
${ }^{9}$ Véase J. BALló, X. PÉREZ; La semilla inmortal. Los argumentos universales en el cine, Barcelona, 1997. Los autores recogen los siguientes "argumentos universales": Jasón y los argonautas, La Odisea, La Eneida, El Mesías, El Maligno, Orestes, Antígona, El jardín de los cerezos, El sueño de una noche de verano, La Bella y la Bestia, Romeo y Julieta, Madame Bovary, Don Juan, La Cenicienta, Macbeth, Fausto, Jekill y Hyde, Edipo, El castillo, Prometeo y Pigmalión, Orfeo. En la misma línea se inscribe R. GUBERN, Máscaras de la ficción, Barcelona, 2002. El autor plantea el estudio de multitud de personajes agrupados por núcleos temáticos; a saber: la sombra y el reflejo (Peter Schlemihl, Balduin, Dorian Gray); los enigmas de la vida (Víctor Frankenstein, doctor Moreau); la mujer depredadora (Carmen, Lulú, Lola-Lola, Rose Loomis, Lolita, Baby Doll); la pulsión aventurera (capitán Ahab, Flash Gordon, Indiana Jones); la vida es sueño (Alicia, Dorothy Gale, Little Nemo); la culpa (Rodion Raskólnikov, Hans Beckert, Josef K); los placeres pasivos (Severin von Kusiemski, L. B. Jeffries); la razón y los monstruos (Auguste Dupin, Sherlock Holmes, Hank Quinlan); la dualidad del ser (los doctores Jekyll, Griffin y Caligari, el Zorro, el Hombre Enmascarado, Superman); la mujer sublimada (Ayesha, Antinea, Barbarella); voluptuosidad sangrienta (Lord Ruthven, Carmilla, conde Drácula); perdedores (Pierre Gilieth, Pépé le Moko, Jean, Rick, Norma Desmond, Veronika Voss); los años difíciles (Jim Stark, Antoine Doinel); y la máquina emocional (HAL-9000, Robocop, Pinocho, David Swinton).

${ }^{10}$ Entendemos género como un conjunto de reglas que proporcionan a los emisores (autores, guionistas, directores, actores) unas pautas o patrones de producción discursiva y a los destinatarios (espectadores) cánones para hacer el texto más legible. Estas reglas han sido codificadas por la tradición a lo largo de la
} 
c) Tercer nivel: Valores simbólicos. El espectador/analista debe ser capaz de entender cómo se imbrican los diferentes códigos y segmentos significantes (figuras metafóricas y/o metonímicas) en el texto fílmico, cómo se disputan el espacio, y con ello desentrañar el contenido latente del film. Estos códigos y figuras son interpretados como valores simbólicos de un universo cultural determinado. Este último nivel se ocupa por lo tanto del significado connotado profundo (no convencional) de los filmes, que comprende todos los valores culturales que el significante pueda evocar en la mente del receptor. Como bien ha apuntado Juan Antonio Ramírez existe una proximidad nada casual entre la iconología y el sicoanálisis freudiano, y aún siendo más concretos, entre el método panofskyano y el paranoico-crítico daliniano ${ }^{11}$. Aplicado al análisis fílmico, este último nivel ofrece múltiples vías de trabajo como, por ejemplo, el estudio de los códigos cinematográficos (panorámica, plano/contraplano, un género concreto...) en clave simbólica (al igual que hizo Panofsky con la perspectiva y la arquitectura gótica) o el estudio de la presencia en la pantalla de un objeto tecnológico como el coche, bien en una película concreta, bien en un contexto determinado (cine español), bien en un autor

historia, interviniendo de manera decisiva el factor antropológico e ideológico. En el caso del cine, la clasificación en géneros respondió a una exigencia del "studio system" norteamericano, como respuesta a las peculiaridades y demandas del mercado, en paralelo al triunfo del modelo clásico. Cada género posee una poética característica que se manifiesta a través de la repetición de personajes, ambientes, estructuras narrativas y otros rasgos de estilo, que afectan tanto a la forma de la expresión como a la forma del contenido del texto. La dificultad reside en definir con exactitud meridiana esos rasgos o reglas, ya que, evidentemente, no siempre se logra el acuerdo entre autores, espectadores, estudiosos...

${ }^{11}$ Véase J. A. RAMíREZ, "Iconografía e iconología", en V. BozAl (ed.), Historia de las ideas estéticas y de las teorías artísticas contemporáneas, volumen II, Madrid, 1996, pp. 227-44.
(Carlos Saura), con la intención de "desocultar" los valores que nuestra cultura asocia al automóvil ${ }^{12}$.

Siguiendo a Foucault podemos decir que el propio objeto-coche alberga esa multiplicidad de connotaciones, que nos permite definirlo como un espacio cambiante o "heterotópico"13. El filósofo francés define las "heterotopías" como "lugares que están fuera de todos los lugares, aunque, sin embargo, resulten efectivamente localizables" $^{14}$; y las analiza a través de los seis principios de lo que denomina "heterotopología":

1) “(...) no hay probablemente una sola cultura en el mundo que no constituya heterotopías. Tenemos ahí una constante de todo grupo humano. Pero las heterotopías toman evidentemente formas que son muy variadas, y tal vez no se encontraría una sola forma de heterotopía que fuese absolutamente universal". Ejemplo: el colegio ${ }^{15}$.

2) “(...) en el curso de su historia, una sociedad puede hacer que una heterotopía que existe y que no ha dejado de existir funcione de una manera muy diferente; en efecto, cada heterotopía tiene un funcionamiento preciso y determinado en el interior de la sociedad, y la misma heterotopía puede, según la sincronía de la cultura en la

\footnotetext{
${ }^{12}$ Cualquier imagen de un coche, sea una foto, un cuadro o el plano de un film constituye un enunciado que introduce un determinado valor connotativo, lo cual nos permite ir mucho más allá de la referencia inmediata que el código asigna a la palabra "coche".

${ }^{13}$ Foucault expuso esta teoría en su conferencia "Des espaces autres", pronunciada en el Cercle d'Etudes Architecturales de París el 14 de marzo de 1967. Cfr. M. Foucault, "Espacios diferentes", en M. FOUCAULT, Estética, ética y hermenéutica. Obras esenciales, volumen III, Barcelona, 1994, pp. 431-41.

${ }^{14}$ Ibidem, p. 435.
${ }^{15}$ Ibidem, p. 435.
} 
que se encuentra, tener un funcionamiento u otro". Ejemplo: el cementerio ${ }^{16}$.

3) “La heterotopía tiene el poder de yuxtaponer en un solo lugar varios espacios, varios emplazamientos que son por sí mismos incompatibles". Ejemplo: la sala de cine $^{17}$.

4) "Lo más frecuente es que las heterotopías estén ligadas muy a menudo a períodos de tiempo (...). Hay, en primer lugar, heterotopías del tiempo que se acumula hasta el infinito". Ejemplo: el museo. “(...) hay heterotopías que están vinculadas, por el contrario, al tiempo en lo que éste tiene de más fútil, de más pasajero, de más precario, y eso en forma de fiesta". Ejemplo: los pueblos de vacaciones ${ }^{18}$.

5) "Las heterotopías suponen siempre un sistema de apertura y de cerrazón que, a la vez, las aísla y las vuelve penetrables. En general, no se accede a un emplazamiento heterotópico como se entra en un molino. O bien se está constreñido en él (...), o bien hay que someterse a ritos $y$ purificaciones". Ejemplo: la prisión. "Hay otras, por el contrario, que presentan el aspecto de puras y simples aperturas, pero que, por lo general, ocultan curiosas exclusiones; todo el mundo quiere entrar en esos emplazamientos heterotópicos, pero, a decir verdad, eso no es más que una ilusión: se cree penetrar y se está, por el hecho mismo de entrar, excluido". Ejemplo: los moteles americanos de carretera ${ }^{19}$.

6) "Finalmente el último rasgo de las heterotopías es que, en relación con el resto del espacio, cumplen una función. Ésta se despliega entre dos polos opuestos. O bien desempeñan el papel de crear un espacio de

\footnotetext{
${ }^{16}$ Ibidem, p. 436.

${ }^{17}$ Ibidem, pp. 437-8.

${ }^{18}$ Ibidem, pp. 438-9.

${ }^{19}$ Ibidem, p. 439.
}

ilusión que denuncia como más ilusorio aún todo el espacio real, todos esos espacios en cuyo interior la vida humana está compartimentada". Ejemplo: el burdel. "O bien, por el contrario, crean un espacio distinto, otro espacio real, tan perfecto, tan meticuloso, tan bien repartido como a su vez el nuestro está ordenado, mal dispuesto y embrollado". Ejemplo: colonias de los jesuitas de Paraguay ${ }^{20}$.

Aunque Foucault no menciona el coche como uno de estos espacios heterotópicos, concluye su ensayo apuntando que el barco es la heterotopía por execelencia. De hecho no es complicado aplicar los seis principios de la heterotopología a este elemento. El coche nos encierra en una cápsula hermética de chapa y cristal, cuyo interior está diseñado de acuerdo con unos parámetros de comodidad y buen gusto que convierten al vehículo en una prolongación de nuestro hogar convencional. Porque el vehículo tiene la capacidad de yuxtaponer espacios distintos: casa, dormitorio, burdel, sala de música... Aparece además inevitablemente ligado a los periodos de tiempo, funciona como una "máquina del tiempo $^{\prime 21}$, que nos abre las puertas de un espacio ilusoriamente real:

"La movilidad sin esfuerzo constituye una especie de dicha irreal, de suspenso de la existencia y de irresponsabilidad. La velocidad tiene como efecto, al integrar el espacio-

${ }^{20}$ Ibidem, p. 440.

${ }^{21}$ Con los nuevos y veloces sistemas de comunicación y transporte surgidos en el siglo XIX el establecimiento de un único patrón horario nacional en Inglaterra llegó a ser una prioridad fundamental: "La diferencia de hora local entre Londres y Bristol, por ejemplo, es de casi veinte minutos. Esto podía carecer de importancia si se viajaba a caballo o en un carruaje, pero tras la llegada del ferrocarril, si se seguía el horario londinense, se podía llegar a Bristol con casi veinte minutos de adelanto, según la hora local". J. BETTS, "Desarrollo de modernos sistemas de medición de tiempo. De los péndulos a los átomos", en K. LIPPINCOTT (ed.), $E l$ tiempo a través del tiempo, Barcelona, 2000, pp. $136 \mathrm{y}$ 146. 
tiempo, reducir el mundo a dos dimensiones, a una imagen; ésta dispensada de su relieve $y$ de su devenir, nos entrega, en cierta manera, a una suerte de inmovilidad sublime y a una contemplación. (...) Más allá de cien kilómetros por hora hay presunción de eternidad (de neurosis, también, quizá). Esta seguridad de un más allá o de un más acá del mundo es el alimento de la euforia por el automóvil, que nada tiene de un tono activo: es una satisfacción pasiva, pero cuya decoración cambia continuamente" ${ }^{22}$.

Como circulamos en/con él, es inestable ("un pedazo flotante de espacio, un lugar sin lugar", como dice Foucault del barco), se opone a la concepción de "lugar" como cultura localizada en el espacio y en el tiempo, con la identidad que le otorga toda una tradición etnológica ${ }^{23}$. Finalmente, podemos concluir que si hubiese que citar una heterotopía universal esa sería, con el barco y el tren, el automóvil.

\section{EL COCHE Y LAS RELACIONES DE PAREJA EN EL CONTEXTO ESPAÑOL (CINE Y SOCIEDAD)}

Es este un campo de estudio muy amplio que requeriría un libro completo. Nos conformamos, por el momento, con aportar algunas notas que nos sirvan de base para el posterior estudio de la obra de Saura.

Desde sus primeros tiempos el automóvil sirvió para refugio de enamorados, tanto por su aislamiento como por la posibilidad de trasladarlos a un sitio alejado de miradas ajenas. Aunque este sentido del

${ }^{22} \mathrm{~J}$. BAUDRILLARD, El sistema de los objetos, México, 1969, pp. 75-6.

${ }^{23}$ Marc Augé considera como no lugares "tanto las instalaciones necesarias para la circulación acelerada de las personas y bienes (vías rápidas, empalmes de rutas, aeropuertos), como los medios de transporte mismos o los grandes centros comerciales, o también los campos de tránsito prolongado donde se estacionan los refugiados del planeta". Véase M. AUGÉ, Los "no lugares" espacios del anonimato. Una antropología de la sobremodernidad, Barcelona, 1993, pp. 40-41 y 83. coche funciona con mucha fuerza en el ámbito anglosajón ${ }^{24}$, Fernando Díaz-Plaja lo considera como parte inherente de la tradición cultural española:

"En el siglo XVII Quevedo le llamaba celestina y aseguraba que muchas mujeres habían subido doncellas por una portezuela y bajado esperando un hijo por la otra.

A mediados de nuestro siglo los novios no tenían otro lugar donde ir -en los hoteles les pedian el certificado de matrimonio- estacionaban en calles oscuras para sus demostraciones afectuosas con un oído atento al menor ruido de pasos que delatara a un policía y su denuncia subsiguiente, con escándalo de la familia llamada luego a declarar.

${ }^{24}$ Recuérdese la célebre reflexión de John Steinbeck en Cannery Row (1945) sobre la estrecha relación entre el asiento trasero de un Ford $\mathrm{T}$ y la concepción de los hijos: "Someone should write an erudite essay on the moral, physical, and aesthetic effect of the Model T Ford on the American nation. Two generations of Americans knew more about of the Ford coil than the clitoris, about the planetary system of gears than the solar system of stars. With the Model T, part of the concept of private property disappeared. Pliers ceased to be privately owned and a tyre-pump belonged to the last man who had picked it up. Most of the babies of the period were conceived in Model $\mathrm{T}$ Fords and not a few were born in them. The theory of the Anglo-Saxon home became so warped that it never quite recovered". J. STEINBECK, Of Mice and Men and Cannery Row, London, 1972, p. 135. Flink incide en el mismo asunto al indicar que, a finales de los años 20, el asiento trasero del Ford $T$ resultaba mejor que un pajar para los encuentros amorosos. Un juez norteamericano, en relación con unas menores implicadas en estos "crímenes sexuales", sentenció: "the automobile has become a house of prostitution on wheels". Cfr. J. J. FLINK, The Car Culture, Massachusetts, 1976, p. 158. Muchas canciones norteamericanas de las primeras décadas del siglo XX se hacen eco del uso del coche como lugar para consumar los encuentros sexuales: In Your Little Love Mobile, Tumble in a Rumble Seat, Keep Away from the Fellow Who Owns an Automobile; incluso los coches son descritos como pareja en las letras de alguna de ellas: "Mr. Packard and Miss Flivverette have a fling, then, after getting married, conceive a Buick". El tema también inspiraría muchas postales y tiras cómicas en los periódicos. Cfr. D. L. LEWIS, "Sex and the Automobile: From Rumble Seats to Rockin' Vans", D. L. LEWIS (ed.), The Automobile and American Culture. Michigan Quarterly Review, vol. XIX, 4, 1980/vol. XX, 1, 1981, pp. 518-28. 
En la calle oscura o en el bosque. Yendo a caballo yo me he encontrado en la Casa de Campo un «seiscientos» que todavía hoy no comprendo cómo pudo haber llegado hasta allí entre las matas ${ }^{\prime \prime 2}$.

Tampoco hay que olvidar el papel del coche en el flirteo, con elementos como la bocina, que puede tener un valor erótico. En España, Laura Pinilllos, allá por los años 20, ya lo aprovechaba para su canción:

"Yo me vuelvo localpor tener un auto/para por las tardes/con él pasear,/con mis gafas negras,/siempre en el volante/mientras la bocinaltoco sin cesar./Yo quiero un auto, papá,/yo quiero un auto veloz,/de portentoso arranquely de tremenda emoción./Yo quiero un auto, papá,/todo pintado de azul,/para poder escuchar/el delicioso pabú./Un auto pequeño/como el de mi novio,/y con la bocinalde tal variedad,/que al sonar unamos/nuestros pensamientos/sin que se dé cuentalde ello mi papá" ${ }^{\prime 2}$.

Esta tradición se deja sentir con fuerza en el cine español, hasta el punto incluso de permitirnos trazar una historia social a través de los filmes partiendo de la asociación entre el coche y la relación de pareja. Durante los años cuarenta, cuando las alusiones a la realidad del país eran casi inexistentes, en las comedias a medio camino entre las italianas de "teléfonos blancos" y el cine de Hollywood, el automóvil contribuye a crear una imagen liberal de las relaciones de pareja: mujeres ricas, desinhibidas, que viajan solas e incluso utilizan el coche como un recurso eficaz en su estrategia de seducción (Yo no me caso, Juan de Orduña, 1944), accidentes (Aventura, Jerónimo Mihura, 1942) o robos (Idilio en Mallorca, Max Neufeld, 1942) como parte de los enredos del juego amoroso.

Desde mediados de los 50 y durante la década de los 60, en paralelo a la normalización de las relaciones internacionales, el

\footnotetext{
${ }^{25}$ F. DÍAZ-PLAJA, El español y su automóvil, Madrid, 1991, p. 56

${ }^{26}$ Ibidem, p. 9.
}

"baby boom" y el desarrollo económico, se observa la tendencia hacia la consolidación de la pareja. Un ejemplo paradigmático es Ya tenemos coche (Julio Salvador, 1958), película en la que el 600 que se compra su protagonista favorece la consolidación de las tres relaciones de pareja de la diégesis, las tres en forma de matrimonio. Pero si hay un personaje que es capaz de resolver los líos sentimentales (ajenos y propios), contribuyendo a la estabilización de la pareja, ese es sin duda el taxista. Pueden recordarse algunos ejemplos como: Amor sobre ruedas (Ramón Torrado, 1954) y su "remake" Amor a todo gas (Ramón Torrado, 1968), Los ángeles del volante (Ignacio F. Iquino, 1957) y El taxi de los conflictos (José Luis Sáenz de Heredia y Mariano Ozores, 1968).

Durante la década de los 70, el final del franquismo y la apertura contribuyen a normalizar la representación de las relaciones de pareja a través de viejos y nuevos hábitos vinculados al coche: las vacaciones y la figura del "Rodríguez" en Verano 70 (Pedro Lazaga, 1969), las primeras aventuras al volante de una juventud burguesa en Las nenas del mini-mini (Germán Lorente, 1969), la novedosa práctica del "caravaning" en Morbo (Gonzalo Suárez, 1971) o la liberalización de los hábitos sexuales en Sábado, chica, motel, iqué lío! (José Luis Merino, 1975).

Finalmente, en los 80 y 90, cabría destacar la incertidumbre, en paralelo a la crisis de la institución matrimonial y la proliferación del divorcio, como rasgo más sobresaliente en relación con el binomio relación de pareja/coche. Basta un ejemplo para demostrarlo: el desarrollo de la "road movie": A contratiempo (Oscar Ladoire, 1982), Antártida (Manuel Huerga, 1995) o Carreteras secundarias (Emilio Martínez-Lázaro, 1997). 


\section{EL CINE DE SAURA}

\subsection{Caracterización general}

La obra cinematográfica de Carlos Saura aparece determinada por dos aspectos esenciales. El primero consiste en su carácter preferentemente discursivo, es decir, casi siempre es más importante el "cómo se cuenta" (discurso), que "lo que se cuenta" (historia). El texto sauriano suele estimular y provocar un espectador activo, sensible a la contradicción y la heterogeneidad; o lo que es lo mismo, transforma a su consumidor en productor promoviendo el juego de la significación. El segundo aspecto nos habla del carácter unitario de toda la producción del cineasta, fenómeno que en muchas ocasiones impide desentrañar el sentido de uno de los textos si se analiza de manera individualizada ${ }^{27}$. En última instancia no sería para nada arriesgado considerar que esta trabazón es tan fuerte que toda la obra del director aragonés puede llegar a considerarse como un gran universo diegético de carácter unitario (o "gran teatro del mundo" ${ }^{28}$ ), que se rige por leyes concretas (la tensión en las relaciones interpersonales; la presencia del pasado como una fuerza incontrolable; los conflictos familiares; la mezcla indisoluble entre ficción y realidad cuando los protagonistas preparan una obra...) y está poblado por personajes tipo muy próximos entre sí (individuos que viven al margen de la sociedad, todo tipo de burgueses, mujeres rebeldes, mujeres objeto, padres denostados...).

\footnotetext{
${ }^{27}$ Sánchez Vidal lo explica de la siguiente forma: "Además de su evidente progresión temática y lingüística, las películas de Saura suelen tener, de forma consciente o inconsciente, elementos de transición, como si surgiesen unas de algún costillar de las otras". Cfr. A. SÁnCHEZ VIDAL, El cine de Carlos Saura, Zaragoza, 1988, p. 75.

${ }^{28}$ Este término de raigambre calderoniana nos pone más en contacto con la importante relación que une la obra de Saura con el Siglo de Oro español. El director coincide con los artistas (pintores y escritores) de
}

El carácter discursivo, proclive al desarrollo de construcciones alegóricas audiovisuales, y la intertextualidad interna convierten la obra de Saura en una de las más idóneas del cine español para la realización de estudios como el que aquí se presenta. Un tercer rasgo refuerza esta tesis: la variedad de temas abordados por el director a lo largo de 50 años de profesión (a pesar de que la mayoría de los estudios de su obra se hayan orientado hacia la política, la guerra civil o la crítica del régimen franquista). Así, Saura se ha interesado por temas tan universales como las relaciones de pareja, la familia, la infancia o la violencia.

Las relaciones de pareja es una temática que ha tenido un desarrollo homogéneo a lo largo de toda la trayectoria del cineasta. Muchas de sus películas tratan, de algún modo, sobre una historia de amor: malograda (La prima Angélica, 1973), que consigue superar todas las dificultades (Taxi, 1996), truncada por la muerte (Llanto por un bandido, 1963; Deprisa deprisa, 1980; ¡Ay, Carmela!, 1990; y Dispara, 1993) o por la diferencia de edad (Los zancos, 1984). Varios de sus "musicales", como Bodas de sangre (1981), Carmen (1983) o El amor brujo (1986) abordan esta temática de una manera totalmente estilizada, como corresponde a las

esa época en su gusto por representar la realidad a través de la imaginación, por contar dando un rodeo, en su interés por la metaficcionalidad, los desdoblamientos de personalidad o los espejos. Aspectos todos que configuran ese hermetismo, esa cierta sensación de misterio característica de ambas estéticas. Pero existen también en sus películas referencias más puntuales, como la reinterpretación de El curioso impertinente (relato incluido en la primera parte de El Quijote) que se lleva a cabo en Stress es tres tres (1968) o las citas de Baltasar Gracián (El Criticón) incluidas en Elisa, vida mía (1976) (que toma su título de una égloga de Garcilaso de la Vega) y Goya en Burdeos (1999). Además están, por supuesto, El Dorado (1987) y La noche oscura (1988), dos aproximaciones directas a este período histórico. 
obras originales en que se basan las películas.

Durante el período que va de 1967 a 1969 (Peppermint frappé, 1967; Stress es tres tres, 1968; y La madriguera, 1969), Saura se dedicó exclusivamente al estudio de la pareja burguesa ${ }^{29}$. En los tres filmes citados se ponen de manifiesto las contradicciones hombre-mujer, a través de la constatación de que en la sociedad española, a pesar de su reciente modernización, sigue perviviendo una imagen de la mujer anclada en el pasado medieval. El fracaso definitivo aparece en La madriguera con la muerte del matrimonio protagonista, sobre el que, a diferencia de los otros dos títulos, no planea la amenaza de la infidelidad.

A mediados de los 70 el director abandona este arquetipo de mujer burguesa, liberando a sus personajes femeninos de viejas servidumbres para equipararlos intelectualmente al hombre. Buenos ejemplos son Elisa, vida mía (1976) y Los ojos vendados (1978), donde las protagonistas se separan de sus respectivos maridos ${ }^{30}$. Por su parte, Mamá cumple 100 años (1979) aborda la infidelidad con el tono desenfadado que corresponde a una comedia ${ }^{31}$.

3.2. Estudio: el coche y la relación de pareja a través de los filmes

\subsubsection{Peppermint frappé (1967)}

Julián vive en Cuenca donde ejerce su profesión de radiólogo, sin apenas contacto con el exterior. Esta existencia aislada, casi recluida, se interrumpe con la llegada

\footnotetext{
${ }^{29}$ Muy ajustadamente Marcel Oms habla de "La trilogie du couple". Cfr. M. OMS, Carlos Saura, Paris, 1981, pp. 37-45.

${ }^{30}$ La crisis de pareja reaparece más recientemente en Pajarico (1997) y Tango (1998).

${ }^{31}$ Quizá pudiera verse un paralelismo entre estos últimos títulos y la evolución de su relación con Geraldine Chaplin que se rompió definitivamente en 1979.
}

de Pablo, amigo de la infancia, y su joven mujer Elena, con la que acaba de contraer matrimonio. Julián se siente atraído por Elena desde el primer momento porque la identifica con una muchacha que vio tocando el tambor en la Semana Santa de Calanda. Dominado por esta obsesión, el radiólogo intenta transformar a Ana, su enfermera, a imagen y semejanza de la esposa de su amigo ${ }^{32}$. El matrimonio, que conoce esta manía, se burla cruelmente de Pablo. El médico se venga administrándoles un somnífero e introduciéndolos en su coche, que luego despeña por un barranco. Ana le espera en la casa, definitivamente transmutada.

El interés de Saura por transgredir lo externo, por diseccionar individuos y objetos presente en La caza (1965) evoluciona con Peppermint frappé hacia la prospección sicológica, focalizada en el personaje de Julián (interpretado por José Luis López Vázquez). Julián es un burgués provinciano ya cuarentón que se ha visto desbordado por los cambios introducidos en España en los inicios de la sociedad de consumo: le gustan las revistas de moda; conduce un vehículo de reciente fabricación, un Seat 850; hace gimnasia con un simulador de remo... Sin embargo todo esto no ha servido para cambiar su mentalidad (en este sentido puede verse al personaje protagonista como una clara metáfora de la sociedad española desarrollista de finales de los años 60), profundamente afectada por una

\footnotetext{
${ }^{32}$ Existe una clara relación entre Elena y Ana (ambas interpretadas por Geraldine Chaplin) y las maniquíes "art decó" de cera y "papier mâché" parisinas de los años veinte, nacidas en paralelo al manifiesto surrealista de André Breton. Para esculpir sus cuerpos, los diseñadores se inspiraron en dibujos de modas consiguiendo lograr unas figuras altamente estilizadas que no provenían de modelos vivos sino del cuerpo ideal de la mujer moderna. Cfr. H. SCHWARTZ, La cultura de la copia. Parecidos sorprendentes, facsímiles insólitos, Madrid, 1998, p. 106.
} 
sexualidad reprimida a causa de la estricta formación religiosa recibida en la infancia.

La presencia del coche en Peppermint frappé posee una clara función vertebradora dentro del discurso, tanto del desarrollo de la trama de suspense (que desemboca en el asesinato final), como de la evolución sicológica del protagonista que la acompaña; pero además, al mismo tiempo, refleja la condición del elemento como objeto privilegiado de la sociedad de consumo sobre el que proyectamos nuestros más profundos deseos.

Con este sentido funciona la secuencia del film que nos interesa, la del recorrido turístico por Cuenca que realizan, nada más conocerse, Julián y Elena. El segmento se inicia con los tres amigos subidos en el Corvette rojo, pero Pablo se va pronto dejando que sea Julián quien le muestre la ciudad a Elena. El médico se apropia del poder de atracción del coche, y para demostrarlo Saura construye una alegoría audiovisual que representa el encuentro sexual entre ambos (ahora el color rojo representa definitivamente el Eros libre y triunfante): desde el interior del Corvette Elena invita a Julián a que conduzca, él accede dubitativo porque dice que no sabe manejarlo, pero ella toca el cambio de marchas y luego la llave de contacto (metáforas de la iniciación del acto sexual que pasaron desapercibidas para la censura [lam. 1]); a continuación la planificación del viaje contribuye a la progresiva integración (cada vez se recurre a planos más amplios) del vehículo en el paisaje (láms. 2 y 3). El paseo en automóvil concluye en la peluquería, donde el médico termina de saciar su ego: cuando pregunta a Elena si se habría casado con él, ella le contesta con un indiferente «¿por qué no?».

El sentido positivo de esta secuencia será borrado a lo largo del discurso audiovisual por las nuevas funciones asociadas al Corvette rojo. En primer lugar, éste se con- vierte en uno de los elementos que configuran la cruel burla de Pablo y Elena: Pablo pide a su amigo Julián que se ponga de espaldas y cuando éste se da la vuelta observa a Elena tocando un tambor (ella imita a la mujer de Calanda) iluminada desde atrás (ya casi es de noche) por los faros del Corvette rojo. Al final del film, Julián empleará el coche para despeñar a sus dos amigos por un barranco. Con ello se completa el ciclo simbólico Eros-Thanatos ${ }^{33}$.

\subsubsection{Stress es tres tres (1968)}

Fernando, promotor inmobiliario, viaja en coche de Madrid a Almería acompañado por Teresa, su mujer y Antonio, su amigo y arquitecto, para ver unos terrenos. En el ánimo del marido se esconde la sospecha de que los otros dos le engañan. Después de auxiliar a las víctimas de un accidente y de visitar a la tía de Fernando, los tres viajeros llegan a una playa donde se detienen para bañarse. Un poco por darle celos y otro por juego, Antonio y Teresa flirtean y se besan, mientras, el marido observa en la distancia. Después de imaginar que se venga matando a Antonio, Fernando da por concluido el viaje y emprenden el regreso a Madrid. El promotor comenta en el coche que ya tendrán ocasión de volver a ver los terrenos, pero los dos solos...

\footnotetext{
${ }^{33}$ Como recuerda Revilla: "Por otra parte, algunos psicólogos norteamericanos han aludido a una presunta relación para-sexual o pseudo-sexual del varón con su automóvil, patentizada en los cuidados, a menudo exagerados, que le prodiga. La iconografía publicitaria responde a ideas semejantes cuando asocia con tanta frecuencia la visión del automóvil a la de hermosas e insinuantes muchachas: como dos manifestaciones de una misma realidad. En fin, no hay que desdeñar la equivalencia simbólica automóvil-muerte, reforzada por las continuas informaciones acerca de accidentes de tráfico. De hecho, numerosas encuestas señalan que ésta es una de las formas de muerte más temidas por el hombre actual. He aquí un simbolismo que pudiera coincidir con el anterior: Eros-Thanatos, una vez más, el automóvil en cuanto clave al propio tiempo erótica y mortífera". F. REVILLA, Diccionario de iconografía, voz “automóvil", Madrid, 1990.
} 
Stress es tres tres puede definirse como una especie de boceto en el que se acumulan gran cantidad de temas sin definir ${ }^{34}$. Las dos ideas principales del discurso: una preocupación de corte ecologista por el estrés o la polución y el triángulo amoroso formado por los protagonistas (Fernando; su mujer, Teresa; y Antonio, el amigo de ambos), no terminan de quedar bien ensambladas ${ }^{35}$.

Saura recurre a una férrea linealidad espacio-temporal ${ }^{36}$, que descansa plenamente en el desplazamiento en automóvil, concediendo una importancia inusitada al comportamiento de los protagonistas y a las relaciones que se establecen entre ellos, recluidos en el reducido espacio del Dodge de Fernando (Lám. 4). Esta identificación entre estructura narrativa y viaje permite considerar la película como una "road movie" $^{37}$, aunque como Fiddian y Evans

\section{-}

${ }^{34}$ El propio cineasta lo ha considerado así, explicándolo en función de dos factores: "por un lado, de la forma de estar realizada la película, por su improvisación; y por otro porque eso es coherente con la historia o con la no-historia que se cuenta. Esa inmadurez, esa falta de terminar las cosas, ese apuntamiento de muchas cosas y no resolución de ninguna, me parece que es parte intrínseca de la narración. Es verdad que es una película de apunte, de apuntar una serie de cosas, mucho más que una película en un sentido total de la palabra". E. BRASÓ, Carlos Saura, Madrid, 1974., p. 210.

${ }^{35}$ Cfr. A. SÁNCHEZ VIDAL, El cine de Carlos Saura, op. cit., pp. 60-1.

${ }^{36}$ El tiempo diegético son aproximadamente doce horas, desde la salida por la mañana de Madrid hasta el inicio del regreso desde Almería por la noche.

${ }^{37}$ Por ello es posible descomponerla en función de las paradas que realizan los protagonistas: descanso en el campo solicitado por Teresa; parada para socorrer a las víctimas de un accidente y posterior traslado de una mujer herida al pueblo más cercano; viaje a la casa de la tía de Fernando; la playa de Almería; inicio del viaje de regreso a Madrid. No debe pasarse por alto el año de realización del film, 1968, fecha en la que todavía no se puede hablar de una institucionalización del género "road movie" en Estados Unidos; todavía no se ha estrenado Easy Rider (Buscando mi destino, han precisado: "In Saura's film the journey takes in a route along the rocky shores of sexual politics, particulary in so far as these are related to areas surrounding problems raised by marriage" ${ }^{\prime 38}$.

Stress es tres tres introduce la identificación del matrimonio con un largo viaje lleno de obstáculos, o lo que es lo mismo, el desplazamiento por carretera como metáfora del fracaso de la relación de pareja. Por ello no se debe pasar por alto el hecho de que el itinerario conduzca a unos espacios cada vez más primitivos ${ }^{39}$; gradúe el progresivo aumento de la tensión sicológica de Fernando, y, por último, no concluya: el film se cierra cuando el coche abandona la playa de Almería para regresar a Madrid, culminación de la imagen del matrimonio como "camino cortado". El principal acontecimiento sobre el que pivota esta interpretación es el accidente de tráfico que encuentran los protagonistas. Saura presenta las impactantes imágenes de un coche volcado, presa de las llamas, con el conductor atrapado en el interior (Lám. 5); más suerte tiene su mujer, a la que trasladan, herida, al pueblo más cercano. Esta separación anticipa el distanciamiento de la pareja protagonista $^{40}$ : Teresa justifica su extraño compor-

Dennis Hopper, 1969), que suele considerarse como la inauguradora del género.

${ }^{38}$ R. W. FIDDIAN, P. W. EVANS; "Stress es tres, tres or three into two won't go", en R. W. FIDDIAN, P. W. EVANS; Challenges to Authority: Fiction and Film in Contemporary Spain, London, 1988, p. 73.

${ }^{39}$ Cfr. M. D'LugO, The Films of Carlos Saura. The Practice of Seeing, New Jersey, 1991, p. 80. No en vano la última parte de la película transcurre en Almería, una de las zonas más periféricas de la España del momento (cuando su árida geografía estaba siendo explotada por el spaghetti western).

${ }^{40}$ De esta forma funciona en sentido contrario a la célebre secuencia de la visita a Pompeya del matrimonio burgués británico en crisis de Viaggio in Italia (Te querré siempre, Roberto Rossellini, 1953), episodio que anticipa su inesperada reconciliación final. Allí, Catherine y Alexander Joyce (Ingrid Bergman y George Sanders) contemplan, gracias a la escayola líquida 
tamiento en casa de la tía Matilde por la fuerte impresión que le causó el accidente, cuando en realidad se debe al trato que recibe por parte de su marido ${ }^{41}$; más tarde Fernando se muestra muy frívolo al relatarle el suceso a su tía, mientras Teresa se molesta por su comportamiento.

La identificación del matrimonio con una carretera o un viaje lleno de obstáculos no es nueva en el cine. Podemos mencionar al menos dos precedentes. El primero es Luna de miel (Honeymoon, Michael Powell, 1959), coproducción hispano-inglesa donde se relata el periplo por España de una pareja británica, Kit y Anna Kelly, y el insistente acoso a que los somete el bailarín Antonio, locamente enamorado de ella, que había sido bailarina profesional en el pasado. Durante uno de los viajes en su lujoso automóvil el matrimonio tiene la siguiente conversación ${ }^{42}$ :

Kit: Buena carretera, si fueran todas iguales...

Anna: Sería un poco aburrido.

Kit: Quizás tengas razón, hay que alternar lo áspero con lo suave.

Anna: Sí.

Kit: Como en el matrimonio.

Anna: Sí.

Kit: He pensado mucho en ello, el matrimonio es un camino largo que tiene un principio y un fin; dos seres que viajan juntos con la diferencia de que en vez de durar una o dos horas dura toda la vida. Empiezas creyendo que la carretera es suave y llana [atraviesan unos baches] y de repente te das el batacazo.

vertida sobre los huecos que aparecen en el mar de ceniza, cómo el Vesubio ha conservado intacto el momento mismo en el que una pareja se estaba abrazando: el amor eternizado adquiere forma y volumen, abandonando para siempre el "vacío" al que (aparentemente) había sido condenado por la erupción volcánica.

${ }^{41}$ La frase de Fernando: «Yo no tengo la culpa de lo que ha pasado", adquiere de esta forma el sentido de "Yo no tengo la culpa de que nuestro matrimonio sea un fracaso".

${ }^{42}$ El guión de la película es de Michael Powell y Luis Escobar.
Anna: No creía que fueras capaz de filosofar...

Kit: Soy un poco anticuado, un hombre para una sola mujer; un amor, un hogar; me quieres o me dejas...

Anna: Te quiero.

Kit: Sin reservas, hasta que la muerte nos separe...

Anna: Eso es.

Casi una década después Stanley Donen reconduciría esta asociación de ideas hacia un tratamiento más ácido para poder desarrollarla plenamente en Two for the Road (Dos en la carretera, 1966), donde sólo la fuerza de la costumbre parece justificar el clásico "happy end". El film concede, además, un interesante protagonismo al MG que conducen por Francia Mark y Joanna al inicio de su relación: las constantes averías del coche que terminarán por provocar un incendio (originado simbólicamente en el motor) permiten construir una metáfora que puede servir de precedente a la secuencia del accidente de la película de Saura, si bien esta última invierte de forma definitiva el planteamiento inicial propuesto por los guionistas de Luna de miel.

\subsubsection{Elisa, vida mía (1976)}

En plena crisis matrimonial, Elisa visita a su padre (Luis), que vive retirado en el campo. Durante su estancia, la relación entre ambos se estrecha mucho. Elisa se separa de su marido (Antonio) y participa con gusto de las actividades de Luis (escritura de un diario, traducciones, clases de teatro en un colegio de monjas) hasta que éste enferma gravemente y muere. Elisa encuentra el cadáver a la vuelta del colegio. Entonces ocupa el lugar de su padre y comienza a reelaborar los textos del diario.

Film experimental, "obra abierta", Elisa, vida mía representa el triunfo absoluto de la densidad discursiva sauriana ${ }^{43}$ en

\footnotetext{
${ }^{43}$ No en vano ha sido tomada como ejemplo en algunos estudios teóricos franceses sobre el hecho
} 
claro detrimento de una historia que apenas tiene relevancia. La complejidad de la cinta viene fundamentalmente determinada por el exacerbamiento de la costumbre del director aragonés por difuminar la línea que separa un plano objetivo ("real", que se corresponde con lo que sucede en la diégesis) de otro subjetivo (lo imaginado por los personajes), hasta provocar que en algunos momentos surjan notables dificultades de comprensión.

La complejidad discursiva de la cinta, sin embargo, no debe hacernos olvidar que, a un nivel puramente temático, contiene un discurso sobre la pareja de carácter negativo que recuerda la trilogía de los 60 : Peppermint frappé, Stress es tres tres y La madriguera. Todos los matrimonios que aparecen en la diégesis de Elisa, vida mía han resultado, con el paso del tiempo, un fracaso.

En primer lugar, tenemos el que forman la hermana de Elisa, Isabel, y Julián (que además ha fructificado en dos hijos: Jacobo y Arancha). Tras la comida de cumpleaños de Luis, Isabel confiesa a Elisa que engaña a su marido.

Luego están Elisa y Antonio. Ella ha decidido pasar una temporada con su padre para meditar, pero terminará decidiendo que no quiere volver con él. Antonio engañó a Elisa con su mejor amiga, Sofía. En la secuencia de su definitiva ruptura (a la que luego volveremos) ella acusa al marido de no ser capaz de darlo todo, mientras éste la considera demasiado posesiva.

El tercer matrimonio pertenece al pasado, ya que es el que formaron Luis y la madre de Elisa. Luis la abandonó (al menos así lo recrea él en sus escritos) cuando sus

fílmico, como J. AUMONT, M. MARIE; Análisis del film, Barcelona, 1990, pp. 69-72 o A. GAUDREAULT, F. JOST; El relato cinematográfico. Cine y narratología, Barcelona, 1995 , pp. 38,82 y 85. dos hijas (Elisa e Isabel) eran pequeñas. Según el punto de vista de Luis su esposa sufría constantes crisis que dificultaban notablemente la convivencia.

La única pareja que aparece en la película con un sentido positivo es la compuesta por el padre y la hija, cuya unión se refuerza al encontrarse después de tanto tiempo ${ }^{44}$, y que, como ya hemos mencionado, se verá repentinamente interrumpida por la muerte.

Si se analizan conjuntamente todas las escenas en las que los personajes utilizan el automóvil, se puede establecer que el elemento funciona como metáfora de la relación amorosa. Como ya apuntó Gabriel Blanco en su análisis sicoanalítico de la película:

"El coche es un lugar de unión, de hacer juntos un recorrido. Ir en coche con otra persona, en los sueños y fantasías, tiene por eso el sentido de una relación sexual: recordemos que, etimológicamente, la palabra «coito» deriva precisamente del latín «coire», «ir juntos»" ${ }^{\prime \prime 4}$.

La escena en la que se le confiere mayor protagonismo, por convertirse en el escenario mismo ("lugar") donde ésta sucede, es la de la ruptura entre Antonio y Elisa. Veamos primero una sucinta descripción, antes de comentar el sentido que adquiere este segmento dentro del discurso.

\footnotetext{
${ }^{44}$ Tras la ruptura de Elisa con Antonio, Saura se aprovecha de sus procedimientos discursivos habituales ya desplegados desde el inicio del film (en la imaginación de Luis su mujer es interpretada también por Geraldine Chaplin y él se proyecta al pasado con su aspecto actual), para hacer incurrir al personaje protagonista en un trance edípico: aparece acariciando a Geraldine Chaplin, sin quedar claro si se trata de su mujer o su hija (quizás ambas). Cfr. A. SÁNCHEZ VIDAL, El cine de Carlos Saura, op. cit., p. 121.

${ }^{45}$ Véase G. BlANCO, "Cine y Psicoanálisis: Elisa vida mía", Cinema 2002, 32, 1977, p. 36. Resulta curioso que el autor no se refiera, en relación con este sentido otorgado al elemento, a Peppermint frappé y Stress es tres tres.
} 
Antonio viene a ver a Elisa, y para evitar la presencia de Luis, la pareja sale de la casa y se sube en el Mercedes del marido, que circula hasta detenerse en medio del camino (Lám. 6). A continuación tiene lugar la conversación en el interior del vehículo, con la cámara siempre situada fuera, pero permitiéndosenos escuchar el diálogo como si estuviésemos dentro. Saura alterna constantemente planos desde el lado de ella con otros desde el contrario, el de su marido, pero siempre con los dos personajes en campo. La presencia de los cristales dentro del cuadro introduce también los reflejos de las nubes del cielo que distorsionan las imágenes de manera progresiva (sobre todo el rostro de Elisa), a medida que la conversación subraya la incompatibilidad de la pareja (Lám. 7). Por fin, Elisa abandona el coche de su marido, negándose a que la lleve de vuelta a la casa de su padre.

El espacio cerrado del Mercedes representa el bloqueo sentimental de Elisa, las nubes que distorsionan las imágenes subrayan la progresiva disolución del matrimonio, mientras el montaje dialéctico plano/contraplano adquiere un sentido claro como la puesta en escena de la incompatibilidad de la pareja (los dos sostienen posturas irreconciliables), aspecto que ya se manifiesta simbólicamente, de acuerdo con la lógica antes expuesta, por el mero hecho de que la ruptura se produzca en un automóvil estático ${ }^{46}$. La salida del personaje a la campiña segoviana representa su liberación, aunque también su soledad, el inicio de su nueva vida ${ }^{47}$.

\footnotetext{
${ }^{46}$ Si viajar juntos en coche es metáfora de la pareja, el coche parado significa, tanto en sentido figurado como real, que la relación "no va a ningún sitio".

${ }^{47}$ De forma análoga interpretan la escena E. LARRAZ, "Elisa et l' androgyne", en VV AA, Le cinéma de Carlos Saura. Actes du Colloque sur le cinéma de Carlos Saura des 1 et 2 février 1983, Bordeaux, 1984, pp. 215, 220 y 222; J. HopeWELL, El cine después de Franco (19731988), Madrid, 1989, p. 255 y A. SÁNCHEZ VIDAL, El
}

Otras escenas menos relevantes con este mismo sentido serían las que identifican el viaje en automóvil en solitario como metáfora del fracaso de la relación:

- La madre de Elisa llega en un coche de policía para reconocer el cadáver de su marido (en una de las elucubraciones de Luis).

- Elisa acude sola a Segovia en el 127 para llamar a Antonio.

- Va en taxi a casa de la amante de éste (relato a su padre).

- Antonio llega en su Mercedes para hablar con ella.

- Elisa va en taxi a ver a su padre enfermo en Madrid (en la versión definitiva que se presenta al espectador del texto en el que trabajaba Luis [Lám. 8]).

- Elisa regresa sola del colegio de monjas.

La única ocasión en la que el automóvil adquiere un sentido positivo (ir juntos $=$ relación amorosa) es el viaje de Elisa y Luis al colegio de monjas en el Seat $127^{48}$.

cine de Carlos Saura, op. cit., pp. 120-1. El interior del coche tiene su paralelo en la cabina de teléfonos desde la que Elisa había llamado a Antonio en Segovia para pedirle una prórroga de diez días; allí la cámara también permanecía fuera pero se nos permitía escuchar la voz de ella. La secuencia de la primera salida de la casa (para llamar a Antonio) representa el inicio del proceso de "aprendizaje" seguido por Elisa, mientras la secuencia del Mercedes es su verdadero punto de inflexión: su salida del coche representa el definitivo abandono de Antonio, que confirma su intención de desprenderse de todas las ataduras que la unen al mundo exterior para seguir los pasos de su padre.

48 Todo lo contrario sucede con el Seat 131 de Julián que trae y se lleva fugazmente a la pareja que ya no tiene sentido. Aquí Saura introduce de nuevo la referencia a los problemas de la masificación del tráfico automovilístico en relación con el fracaso sentimental (explotada en Stress es tres tres) a través de la prisa que tiene Julián por regresar: «Bueno y nosotros deprisa, que no quiero cogerlo al llegar a Madrid». 


\subsubsection{Los ojos vendados (1978)}

Su participación en un Comité de denuncia contra los regímenes dictatoriales impulsa a Luis, profesor de teatro y director escénico, a preparar una obra sobre la tortura. El papel de protagonista (una mujer argentina que ha sido secuestrada y torturada) se lo ofrece a su amiga Emilia, que está muy interesada en la interpretación. Luis empieza a recibir anónimos para que abandone el proyecto. Emilia riñe con su marido y acude a su casa, los dos inician una relación amorosa. Prosiguen los ensayos. Luis es agredido brutalmente en su casa por unos desconocidos. El día del estreno dos hombres disparan con ametralladoras contra los actores durante la representación.

Elisa, vida mía es el final de un camino: supone la cumbre de la plenitud creadora de Saura, pero también el comienzo de otro: introduce una vertiente lúdica que convierte al autor-manipulador del discurso en protagonista. Así, en Los ojos vendados Saura se enfrenta de nuevo con el tema de la concepción de la obra creativa, pero su identificación con el personaje protagonista emerge de una manera mucho más clara que en Elisa, vida mía ${ }^{49}$.

La presencia del automóvil en la película adquiere un importante valor metafórico también muy cercano a Elisa, vida mía; así, reaparece o se continua el discurso negativo sobre la pareja a través de las diversas secuencias en las que el automóvil actúa como metáfora del fracaso sentimental. Su estudio nos permitirá reconstruir el

\footnotetext{
${ }^{49}$ Sabemos que al director aragonés se le ocurrió hacer la película en circunstancias similares a las de Luis, cuando en 1977 formó parte de la presidencia del "Tribunal Rusell" (contra la tortura en América Latina) y vio declarar a una mujer con gafas de sol similar a la que ve Luis y luego identifica con Emilia. Cfr. C. SAURA, "Escribe Carlos Saura sobre Los ojos vendados", Fotogramas, 1.543, 1978, p. 20.
}

proceso de la relación amorosa entendida como secuestro-tortura.

Luis todavía no ha iniciado su relación con Emilia, pero ella ya se ha incorporado a la escuela de interpretación. Mientras da clase a sus alumnos, el profesor recuerda su primer encuentro con ella y su marido (Manuel). La secuencia se inicia con la cámara situada a un lado del camino (nuevamente en plena campiña segoviana) con el Citroën GS de Luis que emerge desde el fondo, es decir, de manera bastante similar al comienzo de Elisa, vida mía. Luis detiene su vehículo porque sufre un cólico y se tumba en medio del campo. Otro coche llega por el camino, es un Renault 12 donde viaja la pareja formada por Manuel y Emilia, que sobrepasa un poco al coche de Luis y da marcha atrás para socorrerlo (="el matrimonio se interrumpe").

En pleno apogeo de su relación amorosa Luis y Emilia regresan al lugar en el que se conocieron. La secuencia está precedida de un primer plano de Emilia, que durante un ensayo (recreando la historia del secuestro) pronuncia las siguientes palabras: «viajamos a gran velocidad», a continuación se inicia la música de Purcell y hay un corte seco a plano general de un paisaje segoviano con panorámica que introduce en campo un coche (el de Luis) que circula por una carretera serpenteante, la cámara lo acompaña hasta que (ya sin música) se produce corte a plano medio de la pareja que conversa animadamente en el interior del Citroën (Lám. 9). Sin embargo, cuando llegan al lugar donde se conocieron, Luis se tira en el campo y llora (reaparece la música), pide a Emilia que nunca lo abandone. Los dos se abrazan acostados.

Emilia sufre una crisis: llora, le dice a Luis que necesita algo que llene su vida. Acude a su antigua casa para recoger sus cosas (su marido no está). Mientras saca la ropa del armario del dormitorio se fija en la 
cama, se tumba en ella y se envuelve en una colcha. Regresa a casa de Luis en un taxi, sola, en medio del denso tráfico de Ma$\operatorname{drid}^{50}$.

Emilia interpreta el papel de la mujer torturada durante la representación final de la obra el día del estreno. Las imágenes del secuestro que habían ido apareciendo a lo largo de la película, cuando Luis ideaba ${ }^{51}$ el relato o Emilia lo ensayaba, concluyen ahora con unos planos de ésta tirada en el campo, a un lado de un camino, supuestamente abandonada por los secuestradores; y el lugar es el mismo en el que ella y Luis se encontraron por primera vez (Lám. 10) ${ }^{52}$. Con ello se acentúa el paralelismo entre el papel que representa Emilia dentro de la obra y el que juega en su relación con Luis, a la vez que se define la relación de pareja como un proceso de secuestro (y tortura) ${ }^{53}$

\footnotetext{
${ }^{50}$ Como Elisa cuando va a visitar a su padre enfermo.

${ }^{51}$ Es interesante tener en cuenta que las primeras
} imágenes (la captura de la testigo y su traslado en un Falcon verde) surgen cuando Manuel (dentista) empasta una muela a Luis, con el ruido del torno de fondo.

${ }^{52}$ La composición del primer plano de la escena (muy parecido al que cierra la secuencia ya comentada del viaje en coche), es una cita explícita del cuadro del pintor norteamericano Andrew Wyeth Christina's World, de 1948 (lám. 11), que Emilia había enseñado y explicado a Luis.

${ }^{53}$ Saura había introducido una historia de secuestro similar al final de Cría cuervos (1975), a través del sueño que relata Irene (la hermana de Ana, la niña protagonista interpretada por Ana Torrent); aunque allí se trataba de la identificación negativa de la infancia. Como el director ha explicado: "La infancia es una época de dudas e incomprensiones, el niño está a merced de los caprichos de los adultos que no son capaces de adentrarse en su mundo -cuando lo hacen a lo Walt Disney es todavía peor-. En esa etapa de la vida el miedo a la oscuridad, a lo desconocido, la sensación de soledad, el no entender lo que sucede a tu alrededor, llega a límites insoportables. Quizá yo piense así porque soy un niño de la guerra española del 36 y mis recuerdos infantiles están llenos de bombas, muertos, hambre y penalidades...". A. SÁNCHEZ VIDAL, Retrato de Carlos Saura, Barcelona, 1994, p. 78. que no termina nunca, pues cuando se produce la liberación (ruptura sentimental) se vuelve al punto de partida: la soledad.

\section{CONCLUSIONES}

El desarrollo de una iconología fílmica de raigambre panofskyana completada con los presupuestos de la semiótica se presenta como un campo de estudio necesario para llevar a cabo vías de trabajo como la que aquí se plantea: analizar la presencia del coche en el cine para "desocultar" (Heidegger) los valores culturales que atesora este elemento. El propio automóvil puede considerarse como un lugar "heterotópico" (Foucault), lo que explicaría su facilidad para acumular múltiples sentidos y connotaciones.

El vínculo que une al coche con la relación de pareja es muy fuerte, sobre todo en el contexto norteamericano, y puede calificarse de naturaleza metonímica (con él se flirtea; en él tienen lugar relaciones sexuales; su potencia y tamaño ensalzan a su propietario...) No obstante, esta tradición no le es ajena a la cultura española, y no son pocos los ejemplos cinematográficos que pueden servir para ilustrarla; uno en concreto la conserva incluso en su título: Amor sobre ruedas (Ramón Torrado, 1954).

La obra de Carlos Saura resulta de especial interés porque llega a desarrollar su propio código alegórico audiovisual en torno a la vinculación del automóvil con la relación amorosa/de pareja ${ }^{54}$. Las dos películas que comienzan a fraguarlo son Pep-

\footnotetext{
${ }^{54}$ Con muy buena intuición, Eduardo Bericat, en su estudio sociológico sobre la movilidad espacial, determinaba lo siguiente: "La cultura, en sí misma, está impregnada de elementos de movilidad. Por ejemplo, el director de cine Carlos Saura utilizaba el automóvil en sus primeros films como metáfora de la relación de pareja". Cfr. E. BERICAT AlASTUEY, Sociología de la movilidad espacial. El sedentarismo nómada, Madrid, 1994, p. 235.
} 
permint frappé, con el viaje de Julián y Elena como alegoría de la armonía hombre/mujer; y Stress es tres tres con el desplazamiento del matrimonio Fernando/Teresa y Antonio, el amigo de ambos, de Madrid a Almería, como alegoría del fracaso del matrimonio burgués. Diez años después, otros dos títulos: Elisa, vida mía y Los ojos vendados, terminarán de darle forma coherente: el viaje de la pareja en coche sigue representando la armonía de su relación, el vehículo aparcado su estancamiento, y el viaje solo de uno de sus componentes el fracaso o la indefinición del estado emocional del personaje. Estos motivos visuales reaparecerán posteriormente en otras películas de Saura: Mamá cumple 100 años, Deprisa deprisa, Dulces horas (1981), Antonieta (1982). 


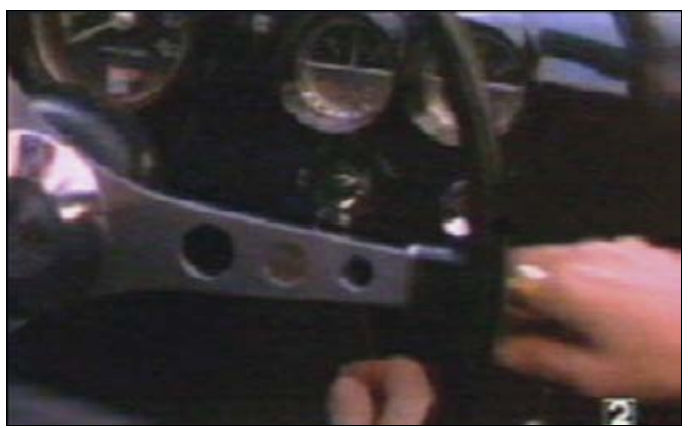

- Lám. 1. La llave de contacto y el cambio de marchas, metáforas del inicio del encuentro sexual (Peppermint frappé, 1967). Fuente: Todos los fotogramas de las películas son de elaboración propia (a partir de grabaciones de la televisión propiedad del autor).

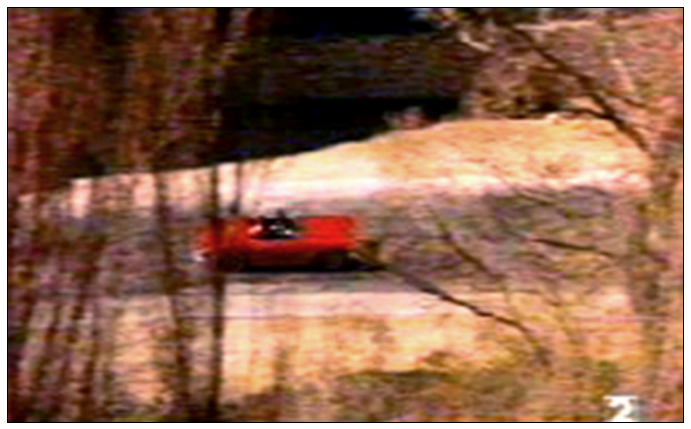

- Lám. 3. El Corvette rojo se funde con el paisaje, metáfora de la cumbre del encuentro sexual (Peppermint frappé, 1967).

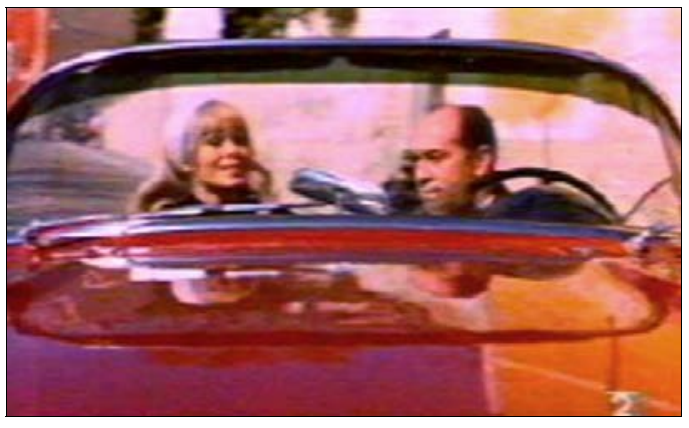

- Lám. 2. La armonía de la pareja (Peppermint frappé, 1967).

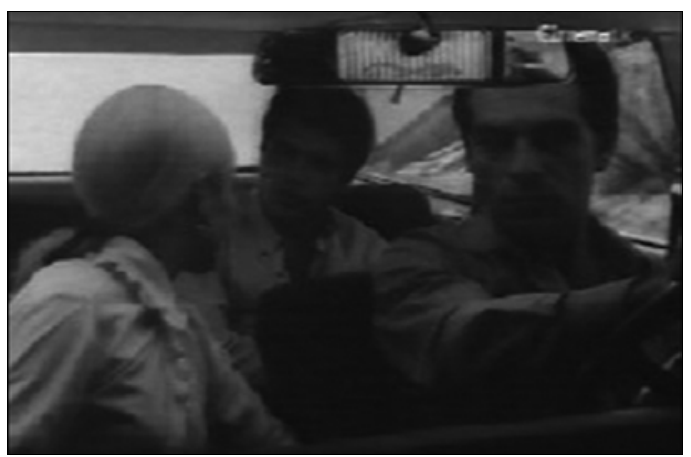

- Lám. 4. Un triángulo inscrito en un automóvil (Stress es tres tres, 1968). 


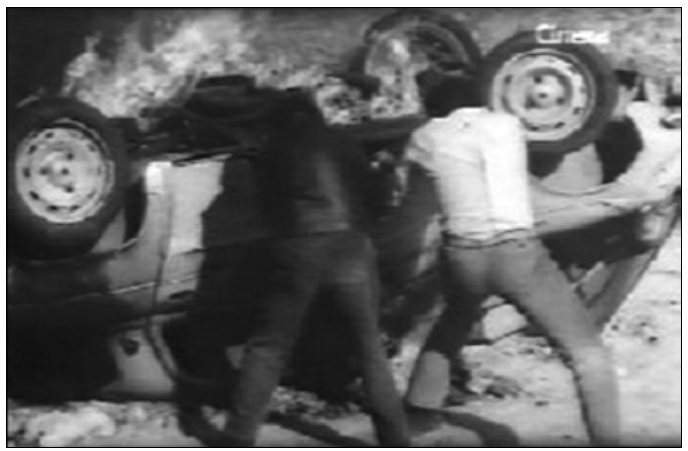

- Lám. 5. La crisis insuperable de la pareja (Stress es tres tres, 1968).

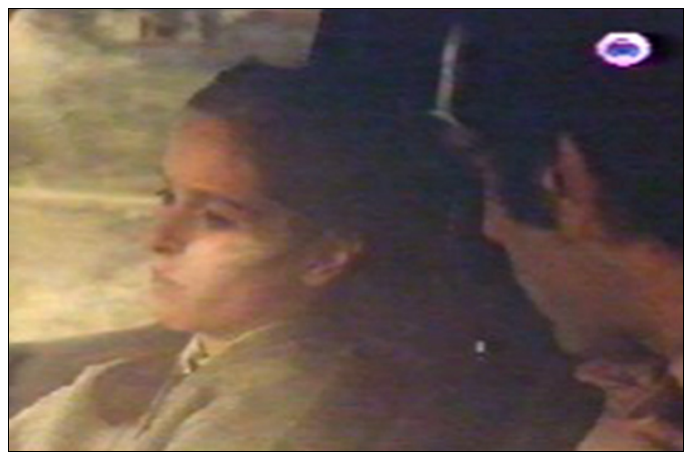

- Lám. 7. La incompatibilidad de la pareja (Elisa, vida mía, 1976).

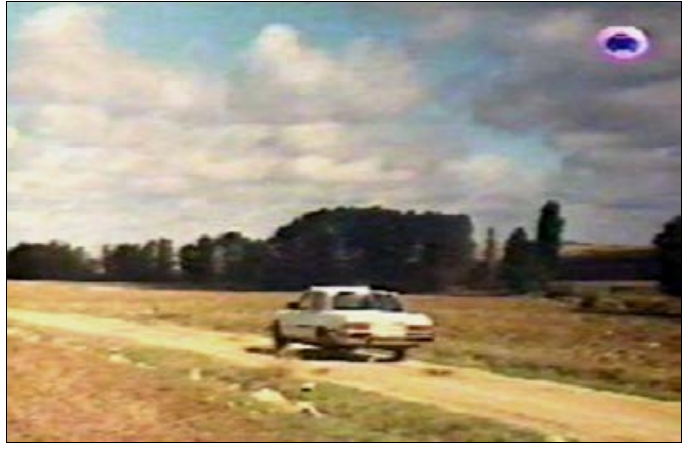

- Lám. 6. La pareja estancada (Elisa, vida mía, 1976).

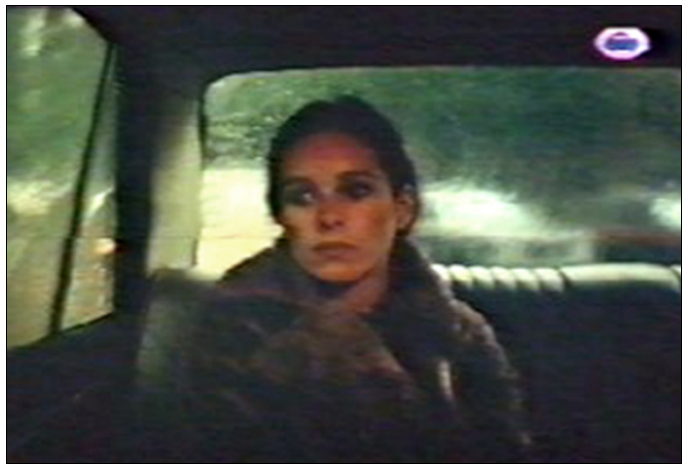

- Lám. 8. La soledad de Elisa (Elisa, vida mía, 1976). 


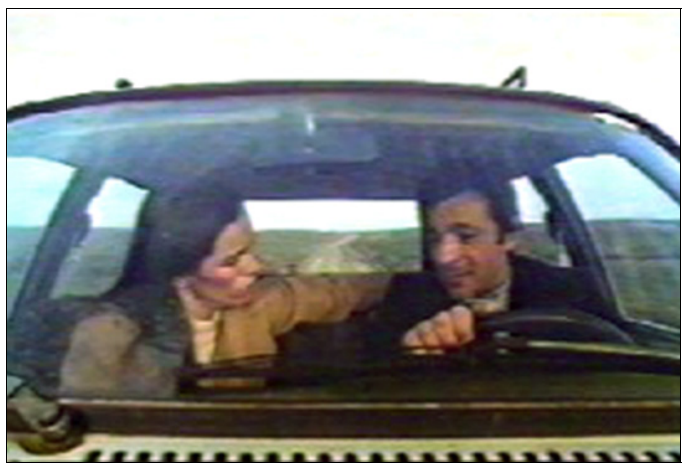

- Lám. 9. La armonía de la pareja (Los ojos vendados, 1978).

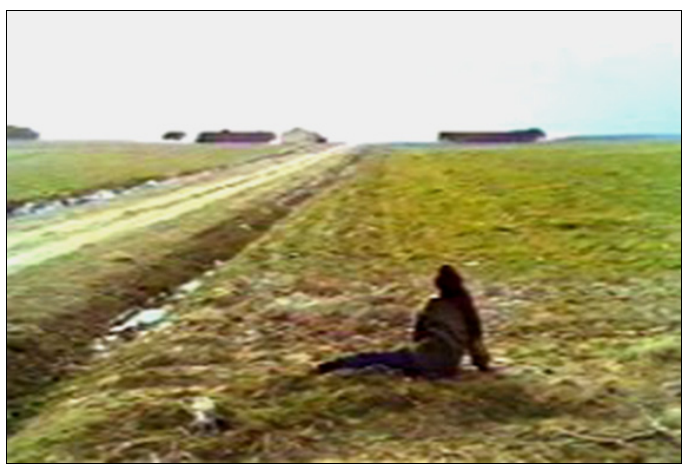

- Lám. 10. La soledad de Emilia (Los ojos vendados, 1978).

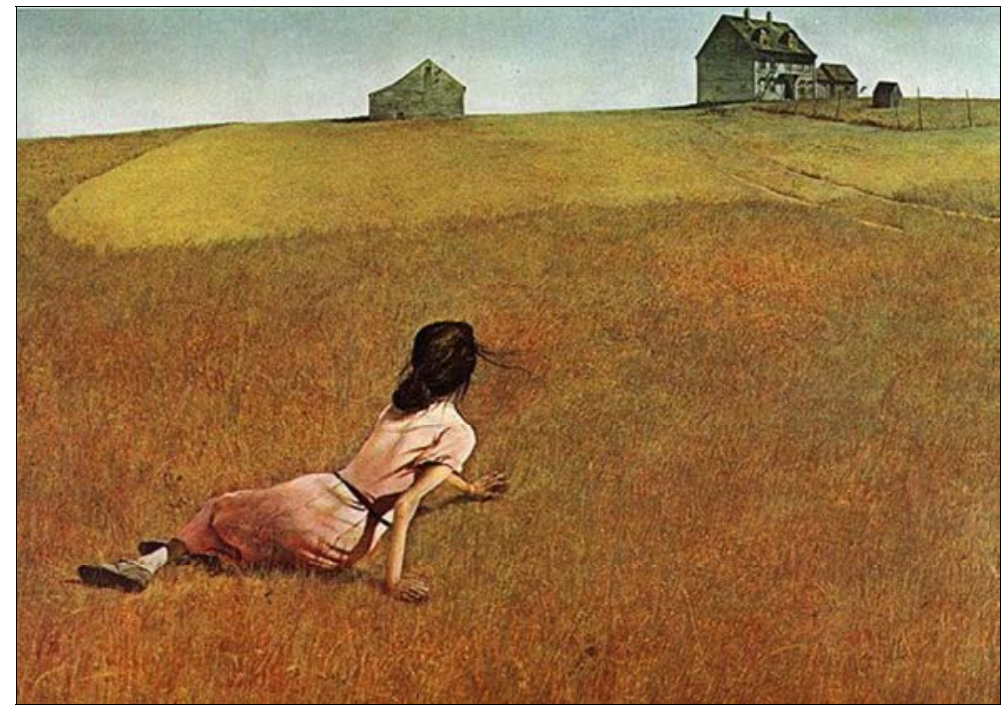

- Lám. 11. Andrew Wyeth, Christina's World (1948), The Museum of Modern Art (New York). Fuente: http://www.artchive.com/ artchive/W/wyeth/christinas_world.jpg.html 